\title{
The Influence of the Family on the Development of Psychosomatic Disorders in Preschool Children With Mental Retardation
}

\author{
Svetlana Aleksandrovna Mugal \\ National Pedagogical Dragomanov University, Kiev, Ukraine
}

\begin{abstract}
The article deals with the systematic analysis of theoretical and practical research materials of native and foreign scholars on a comprehensive study of the family influence on the development of psychosomatic disorders in preschool children with mental retardation. Also, it deals with the current tendency that identifies factors affecting the development of preschool children with MR and the issue of identifying the link between personality characteristics, content, psychotrauma characteristic and frequency of mental trauma. Nowadays the main risk factors of psychosomatic disorders and mental retardation are clarified, which indicate the existence of common pathogenic links of their formation. The crisis of the family in modern society is also considered in this article.
\end{abstract}

Keywords: family, psychosomatic disorders, mental retardation, mental trauma

\section{Introduction}

A characteristic feature currently is the steady accumulation of the number of children with simultaneous affection of somatic and mental health. In Ukraine, one of the most important and urgent issues in a special and clinical psychology is the problem of the psychosomatic disorders study in children with mental retardation (MR) and their impact on the formation and development of the child's personality and the influence of psychosomatic disorders on education, parenting and socialization of the children with MR. Recent years have seen an increasing trend towards the number of children with deviation in mental and physical health, which is caused by biopsychosocial, ecological, economic and other factors and their complex combinations (V. Gavenkoetc., V. Galyabar, V. Pidkorytov, T. Hamaganovaetc., V. Kryshtal, B. Myhaylov, S. Tabachnikov, I. Sergetaetc., O. Lutsenko, G. Beketova, V. Synov, G. Bergmann, and R. Gottlieb). A large number of these children are children with mental retardation, whose numbers are increasing on the background of deterioration in children's health generally.

Most current researches of psychosomatic relations are conducted by experts in medicine (D. M. Isaev, B. V. Mikhailov, M. Vyrshyng, B. Luban-Plotstsa, N. Pezeshkian, G. Y. Pilyagina, O. S. Chaban) or researchers base on data they received during the research of the adult population (O. Y. Berezantsev, G. Ammon, M. Bayer, P. Christian, M. Rad, R. Melzak). Among the child population researches in medicine are rare (G. A. 
Arina, N. A. Kovalenko, J. Klammer, G. P. Mozgova), especially among the preschool children.

Over the past decade, prevalence of psychosomatic disorders (PSD) among preschool child population gained urgency all over the world. Currently in Ukraine for PSD it is typical not only high prevalence but growth of it year after year. The PSD problem in preschool children is urgent and insufficiently explored. In Ukraine, in literature there is generally no information about psychodiagnostic and psychocorrective processes of PSD in preschool children with MR. Pathogenesis is complex. The symptoms are not enough structured and differ due to complaints that do not match objective data. Psychosomatic disorders may be a somatic manifestation of neurotic disorders and mental diseases, conversion disorders and neurotic accompanying of non-psychotic diseases.

The modern view of psychosomatics goes beyond notions of health and disease. Psychosomatics is a bodily reflection of spiritual life, which includes both the physical manifestations of emotions (the result of their disbalance is psychosomatic disorders) and "mirror" of other unconscious processes, bodily channel of consciously unconscious communication. If we look from this side, the body is imagined as a kind of screen, on which symbolic messages of our unconscious are projected. This is the screen, where all the unconscious becomes conscious, or at least it gets the potential opportunity to become it and where the psychological problems of the child, his inner, conscious and unconscious conflicts are reflected in obligate and absolutely compulsory order (A. Smulevych, A. Syrkin, S. Rapoport, and J. Kuchenhoff).

Among the complex of socio-economic problems and the catastrophic deterioration of health of child population special role has increasing of stress situations in everyday life of children and their families. Stress reactions essentially affect not only the immunity and physical development of children, but also contribute to decrease intellectual capacity of the younger generation which directly depends on the features of temperament, conditions of personality formation and parenting style. The instability of structure of the child personality, immaturity of personality and its individual components, and also relations in the family determine the relative easiness of occurrence of psychosomatic disorders (N. A. Belyh, O. V. Temnova, and D. L. Wood).

From the perspective of biopsychosocial paradigm PSD in preschool children with normal mental development and with mental retardation are considered as disorders in the genesis and development of which the significant role is played by impact of mental trauma on the child's condition. Today, scientists have proven the existence of common pathogenetic links in factors that affect the formation and development of PSD and MR in children. This is the impact of genetic predisposition (V. Synov, and J. Frommer); the impact of chronic and acute stress (J. Kuchenholff); infections of TORCH-complex (toxoplasmosis, herpes, cytomegalovirus) and metabolic disorders (N. Leonhardt); and the influence of social factors, educational neglect, etc.

\section{Method}

\section{Participants}

We examined 142 families: 28 families are incomplete and during the test was either mother or father of the child and 114 families where both mother and father were present. In general, experimental psychological study involved 398 people: 142 children and 256 parents.

Among the surveyed group of preschool children with MR were found 94 males, accounting for $66.20 \%$ and 48 females, corresponding to $33.80 \%$ (see Table 1 ). 
Table 1

Distribution of the Surveyed Preschool Children by Gender $(N=142)$

\begin{tabular}{lll}
\hline \multirow{2}{*}{ Gender } & Number of preschool children with MD $N=142$ & $\begin{array}{l}\text { Percentage } \\
100.00\end{array}$ \\
\cline { 2 - 3 } & The absolute number, $N$ & $\%$ \\
\hline Boys & 94 & 66.20 \\
Girls & 48 & 33.80 \\
\hline
\end{tabular}

\section{Procedure}

It is worth noting that in modern society there is a crisis of the family, which is not only on socio-economic level. Training of adults is also insufficient for family life on psychological and pedagogical, social and pedagogical levels, and so on. Lack of strategy of creation and development of the family and family values, lack of consistency in parenting, lack of understanding of the uniqueness and value of each child and each family member, and the inability of parents to predict the effects of education - all this lead to emotional health disorders in the family. Also, one of the factors that influence the occurrence of psychosomatic diseases are attitude of the parents to child's disease. The emergence of psychosomatic disease of a child is based on the attitude of parents to their personality. Disputes in many families, that arise between spouses from time to time, contribute to emergence of psychosomatic problems in the child. It is often impossible to solve these problems and thus help the child without correction of married couple's relations.

All children and their families were examined according to the main criteria of psychological diagnosis such as:

(1) interview (conversation with parents, collecting anamnesis data (report));

(2) monitoring the child; monitoring the relations between parents and relations between parents and child;

(3) study of the micro-social environment;

(4) analysis of products of children's activities.

To diagnose children we used different projective techniques such as "Animal that does not exist", "Three trees", and "Family Drawing".

\section{Data Analysis}

During conversations with parents, we payed attention to: heredity (hereditary diseases: mental, somatic or psychosomatic); personal characteristics of parents; development of pregnancy, peculiarities of childbirth; development of the child from birth to the present time (psychomotor development, development of higher mental functions of the child, the occurrence of sleep or feeding disorders, study of psycho-emotional sphere of the child; occurance of diseases in the early stages of child's development, injury, surgery, intoxication, residual effects of early demage of central nervous system (CNS); pathologically habitual actions etc.); peculiarities of formation and development of the child's relationship with adults and with other children; study of the micro-social environment of the child (material and living conditions and conflicts in the family, the existence of violations in the system "mother-child" "parent-child", defects of parenting, attending child care centers by the child, presence of sisters and brothers, incomplete family, smoking and alcoholism in parents, loss (desease) of parents or near relatives, changing of communication stereotypes, psycho-emotional overload).

The main social circle for preschool child is family. Therefore, while using the method of observation, we paid attention both to the child (behavior, speech, play, etc.) and relationship between parents and relationship between parents and child. 
Also, during the study, we used the method of analysis of products of children's activities to analyze pictures, appliques, stories of children and so on. Due to this method, we analyzed children's pictures that we received during the study of psycho-emotional state of the child, their perception and attitude towards parents, feelings about their place in the family and attitude of their parents to them and the feeling of favorable or conflict situation in the family. This information we obtained using projective techniques such as "Animal that does not exist” (M. Z. Drukarevych), "Family Picture” (K. Mahover, William Wolf), "Three trees” (E. Klessmann).

Due to the technique "Animal that does not exist", we studied the general characteristics of the child, difficulties in communication, aggression, anxiety. Also, this method makes it possible to understand the inner world of the child, how they perceive the environment.

Using the method of "Family Drawing", we were able to find out how the child perceived himself and other members of the family, what feelings he was experiencing in the family, and also we saw the features of intrafamily relations. Children and parents can see and assess the family situation differently. The situation that is positively appreciated on all sides by parents, the child can see and perceive differently. One can understand the causes of many problems and effectively help the child during their solution, knowing how the child sees his family, parents, himself and the world around.

It is worth noting that during the projective technique "Family Drawing", we were faced with certain problems. In families in which there was distorted, conflict and sometimes even hostile relationship-children refused to do this task. Their behavior and mood changed. Some children closed, others showed aggression. But we had to receive information about the relationship in the family. After a while, we offered the children another projective technique "Three trees". The value of this technique is the fact that first the child is offered to draw any three trees on one sheet of paper, and only then compare them with family members of the child. So, during this procedure children gave us detailed information about interfamily relations, the emotional state of the family, their place in the family environment and so on.

\section{Results}

During a comprehensive study of psychoemotional state of the families, we found that each family member has a high level of anxiety. Also there was aggression and understated or overstated self-esteem. In relations between parents and parents' attitude to children there is a conflict. All this leads to the occurance, formation and development of psychosomatic disorders in preschool children with MR.

Also, we have studied preschool children with MR and their parents about the factors of PSD development. The obtained data indicates that the first place took factors of psychosomatic disorders which arose as a result of mental trauma of children due to distorted PSD in the family (there were 73 children or $51.40 \%$ ). The second place took disorders of emotional attachment in early ontogenesis (there were 58 preschool children or $40.85 \%$ ), and the third place took increased anxiety and depression that led to PSD in parents and adults from close environment who care for the child. Parents project on the child their PSD and the child assigns and supports them as his own. It was found 5 people of preschool age with MR (3.52\%). It should be indicated that we had also found a complex combination of factors that influenced the development of psychosomatic disorders in preschool children with MR. We called them other factors. It was found 6 children (4.23\%) (see Table 2).

It is worth mentioning the specifics of experimental study of the influence of family on the development of psychosomatic in children with mental retardation. Parents of these children have had traumatic experiences when they learned that their children have mental retardation. It increased the level of their anxiety and 
contributed in some cases to distortion of PCR, in other cases to removal of parents from children, that led to more sustainable disorder of emotional attachment. Accordingly, it affected the psycho-emotional state of the child and his parents.

Table 2

The Main Factors of Mental Trauma of Surveyed Children in the Family

\begin{tabular}{|l|l|l|}
\hline \multirow{2}{*}{ The main factors of mental trauma of surveyed children in the family } & Number of preschool children with $M D$ \\
\cline { 2 - 3 } & $\begin{array}{l}\text { The absolute } \\
\text { number } \\
(N=142)\end{array}$ & $\begin{array}{l}\text { Percentage (\%) } \\
100,00\end{array}$ \\
\hline Mental trauma of children due to distorted parent-child relationship & 73 & 51.40 \\
\hline Mental trauma of children due to disorders of emotional attachment in early ontogenesis & 58 & 40.85 \\
\hline $\begin{array}{l}\text { Mental trauma of children due to unresolved psychosomatic problems of parents and } \\
\text { adults from the close environment of children that are projected on a child and develop as } \\
\begin{array}{l}\text { PSD in children which were formed by parents and are supported by them. The basis of } \\
\text { PSD in adults were anxiety and depression. }\end{array}\end{array}$ & 5 \\
\hline Other & 6 & 3.52 \\
\hline
\end{tabular}

\section{Conclusion}

Given all the above, it should be noted that the influence of family on the development of psychosomatic disorders is very large, it indicates a high level of prevalence of this pathology and confirms the expediency of early diagnosis and correction as well as the need for the public educative work.

\section{References}

Bondarchuk, O. I. (2001). Family psychology (p. 96). O. Bondarchuk. K .: AIDP.

Kulakov, S. A. (2010). Psychosomatics (p. 384). SPb.

Luria, A. R. (2002). Fundamentals of neuropsychology (p. 384). Publishing Center "Academy".

Mozgova, G. P., \& Mugal, S. O. (2014). Prevalence of psychosomatic disorders among child population (Urgent issues of formation of physician personality in medical students, p. 140). Materials of XIII Int. Scientific and Practical Conference, Kyiv, March 26, 2014.

Mugal, S. A. (2014). Factors affecting the development of psychosomatic disorders in children with mental and speech development. Scientific Journal NPU Dragomanov, 19(27), 140.

Semenovich, A. V. (2012). Neuropsychological correction in childhood (p. 474). A V Semenovich: Genesis.

Vlasova, T. A. (1984). Children with mental retardation (p. 184). SRI defectology APS USSR. 